\title{
Impact of COVID-19 on head and neck cancer advancement measured by the increasing numbers of acute dyspnea cases. What can be improved for the future?
}

Oskar Rosiak ( oskar.rosiak@umed.lodz.pl)

Medical University of Lodz https://orcid.org/0000-0002-5326-4777

Wioletta Pietruszewska

Medical University of Lodz: Uniwersytet Medyczny w Lodzi

Paweł Burduk

Ludwik Rydygier Collegium Medicum: Uniwersytet Mikolaja Kopernika w Toruniu Collegium Medicum im

Ludwika Rydygiera w Bydgoszczy

Paulina Podlawska

Poznan University of Medical Sciences: Uniwersytet Medyczny imienia Karola Marcinkowskiego w

Poznaniu

\section{Bartosz Zakrzewski}

Poznan University of Medical Sciences: Uniwersytet Medyczny imienia Karola Marcinkowskiego w

Poznaniu

\section{Magda Barańska}

Medical University of Lodz: Uniwersytet Medyczny w Lodzi

\section{Magdalena Kowalczyk}

Medical University of Lodz: Uniwersytet Medyczny w Lodzi

Jakub Piątkowski

Medical University of Gdansk: Gdanski Uniwersytet Medyczny

\section{Paweł Solarz}

Ludwik Rydygier Collegium Medicum: Uniwersytet Mikolaja Kopernika w Toruniu Collegium Medicum im Ludwika Rydygiera w Bydgoszczy

\section{Marta Staszak}

Ludwik Rydygier Collegium Medicum: Uniwersytet Mikolaja Kopernika w Toruniu Collegium Medicum im Ludwika Rydygiera w Bydgoszczy

\section{Małgorzata Wierzbicka}

Poznan University of Medical Sciences: Uniwersytet Medyczny imienia Karola Marcinkowskiego w

\section{Poznaniu}

\section{Bogusław Mikaszewski}

Medical University of Gdansk: Gdanski Uniwersytet Medyczny 


\section{Research}

Keywords: COVID-19, dyspnea, head and neck cancer, telehealth, urgent tracheotomy

Posted Date: August 27th, 2021

DOI: https://doi.org/10.21203/rs.3.rs-724114/v2

License: (c) (i) This work is licensed under a Creative Commons Attribution 4.0 International License.

Read Full License 


\section{Abstract}

Background. The COVID-19 pandemic has altered all aspects of how the healthcare system is organized, and impacted patients with head and neck cancer (HNC), who delayed diagnosis and treatment. The result was the increased admission of patients with severe dyspnea and a need for tracheotomy due to extremely advanced HNC. The aim of this study was evaluate the characteristics of two multi-center cohorts of HNC patients admitted for dyspnea.

Methods.. The therapeutic activity of four University Departments of Otolaryngology was studied over two time periods: September-February 2019/2020 and 2020/2021.

Results. A group of $136 \mathrm{HNC}$ patients who underwent tracheotomy in two time cohorts, pre-COVID-19 (N = 59) and COVID-19 ( $\mathrm{N}=77)$, were analyzed. The mean tracheotomy incidence proportion was $1.82 \%$ (SD: 1.12) for the pre-COVID-19 and 3.79\% (SD: 2.76) for the COVID-19 period. A rise in emergency dyspnea was observed in the COVID-19 cohort. In the pre-COVID-19 period, $66 \%$ of patients presented with symptoms for more than a month in comparison to $78 \%$ of patients in COVID-19 times $(p=0.04)$. The number of tracheotomies performed under general anesthesia dropped in favor of local anesthesia during COVID-19 (64\% vs. 56\% respectively) due to extremely advanced HNC. In the COVID-19 cohort, most patients received a telemedicine consultation ( $N=55,71 \%)$ compared to the pre-COVID-19 period ( $N$ $=14,24 \%$ ).

Conclusions. There should be a reorganization of the referral system, an adjustment of treatment capacity for an increased number of HNC patients, and a reserve for more extensive resection and reconstruction surgeries in ENT departments to not hamper future HNC treatment if there is another pandemic wave.

\section{Background}

The COVID-19 pandemic has changed all aspects of the organization of Poland's healthcare system, similar changes occurred across the globe. There has been a huge reduction in the availability of medical services in certain areas of healthcare, especially in primary healthcare and outpatient specialist care [13]. A shift of specialist care to telemedicine visits was observed [4]. These changes affected head and neck cancer (HNC) patients who, due to telemedicine visits, limited inpatient services, or even individual fear of contact with healthcare providers, delayed the diagnosis of cancer and the implementation of treatment. Timeliness of care delivery is regarded as a major quality metric of oncology care [5-7]. The aggressive nature of the majority of HNC negates the ability to defer surgical treatment for a prolonged period $[8,9]$. The consequence of this was (and still is) the admission of patients with extremely highstage oropharyngeal and laryngeal cancers, with severe dyspnea, who urgently require a tracheotomy.

Although cancer patients represent a vulnerable cohort during the Sars-CoV-2 pandemic, the likelihood of SARS-CoV-2-related death is usually lower than the risk arising from advanced disease; however, a severe course of infection with SARS-CoV-2 can lead to the premature death of these patients $[10,11]$. Thus, 
oncology teams around the world have adapted their practice with the aim of protecting patients [12]. Oncological societies have created many recommendations, but precise instructions about routine oncological procedures remain in place. [8, 10,13-15]. A point-based scoring algorithm was developed, the Surgical Prioritization and Ranking Tool and Navigation Aid for Head and Neck Cancer (SPARTAN$H N$ ), which consistently stratifies patients requiring HNC surgical care in the COVID-19 era [16]. Also, an attempt was made to rapidly implement a remote triaging system for the assessment of HNC referrals, utilizing the Head and Neck Cancer Risk Calculator version 2 [17].

However, the real problem is not with patient segregation, but with their delayed and late reporting. The dominant obstruction was getting to the doctor in the first place. The issues with reporting have been observed have been observed in clinical practice since the autumn of 2020 , while now, i.e., in the spring of 2021 and on the verge of another wave of the pandemic, detailed analyses and taking remedial measures are required. The premise for this analysis was how to improve the diagnostics, admission system, and treatment implementation in the age of a pandemic so that patients with extremely advanced cancer seek treatment.

The aim of the study is to compare the clinical features of two multi-center cohorts of HNC patients: "preCOVID-19" (2019/2020) and "COVID-19" (2020/2021), admitted as emergencies for dyspnea to restore the airway and to analyze the cause of the presentation delay.

\section{Methods}

The therapeutic activity in regard of HNC in four University Departments of Otolaryngology (Poznan, Lodz, Gdansk, Bydgoszcz) in two time periods: September-February 2019/2020 and 2020/2021 was compared. The analyzed period was selected in accordance with the duration of the second wave of the pandemic (2020/2021), and the reference period from 2019/2020 was adjusted to it. All four Departments provided services within the normal scope and with all precautionary measures. There were slight organizational differences between the units related to staff fluctuation and periodic lockdowns. Nevertheless, the differences were not the aim of the analysis, and the materials were considered jointly due to the Department profile similarities.

Acute dyspnea was defined as a significant deterioration of respiratory comfort, with inspiratoryexpiratory dyspnea and a decrease in oxygen saturation below 90 . The time from the patient's registration in the emergency room to the procedure (tracheotomy) being performed ranged from 15 to 180 minutes; average 95 minutes, median 60 minutes.

Diagnostic work-up: laryngoscopy or transnasal videolaryngoscopy using flexible scopes was performed, and the necessary information was taken from the patients' documentation, family, or the ex-post evaluation of the surgery. Tumor location and extent and dynamic information on laryngeal mobility were assessed. CT imaging of the larynx was performed before the procedure. 
Treatment: tracheostomy, as the treatment of choice, was performed in all patients. There were two categories of these procedures: under general anesthesia - after transport to the operating room, with the participation of anesthesiologists and after intubating the patient, and under local anesthesia - without the possibility of intubation, in a state of extreme dyspnea, in the ER or in a quickly launched operating room.

The "pre-COVID-19" and "COVID-19" patients were compared. The following variables were analyzed for both cohorts: age, gender, symptom duration, history of documented cardiovascular events, number of telemedicine consultations received, BMI, location of the primary tumor site, and the advancement of the disease based on the TNM system (2017) [18]. The differences in the variables for both pre-COVID-19 and COVID-19 cohorts were analyzed.

The first outcome measure was the incidence proportion of urgent dyspnea cases requiring a tracheotomy in the course of advanced head and neck neoplasms in relation to the total number of all surgical procedures in ENT centers in both periods. The second outcome measure was a detailed description of the specificity of the COVID-19 group.

\section{Statistical analysis}

Statistical analysis was performed using STATISTICA software (Version 13.1, Dell). The incidence proportion for laryngeal dyspnea related to tumors of the head and neck was calculated by dividing the total number of surgical procedures related to emergency dyspnea due to neoplasm by the total number of surgical procedures in each given period in each clinical center individually, with the value presented as a percentage.

The Shapiro-Wilk test was used to assess the normal distribution of the continuous variables, which were summarized using the mean and standard deviation (SD) for normally distributed variables and median values and interquartile ranges for non-normally distributed variables.

Comparisons between the pre-COVID and COVID cohorts for continuous and normally distributed variables within the groups were performed by first performing Levene's test to check for equality of variance between the groups, and upon rejecting the null hypothesis in all instances, the Student's t-test for independent samples was performed. For non-normally distributed continuous variables, the U-MannWhitney test was conducted. To analyze the effect of nominal variables between the cohorts, contingency tables were drawn, and Pearson's Chi-squared test was used, while in populations smaller than five subjects, Fischer's exact test was used. The level of significance used for all the analyses was 2-tailed and set at $P<0.05$.

\section{Results}

The analysis concerns a group of 136 patients who underwent a tracheotomy in two-time cohorts, preCOVID-19 $(\mathrm{N}=59)$ and COVID-19 $(\mathrm{N}=77)$. The study group included 105 men (pre-COVID-19: $N=45 \mathrm{vs.}$ COVID-19: $N=60$ ) and 31 women (pre-COVID-19: $N=14$; COVID-19: $N=17$ ). The median age in the study 
group was 65 years (IQR 10.5), pre-COVID-19: 65 years (IQR 11); COVID-19: 65 years (IQR 10). There were no statistically significant differences in the gender distribution between the periods (Chi-squared test $p=$ 0.82 ) or between the ages of the patients ( $t$-student test $p=0.99$ ).

The mean incidence proportion for all centers was 1.82 (SD: 1.12) for the pre-COVID-19 period of 2019/2020, and 3.79 (SD: 2.76) for the COVID-19 period. A rise in the occurrence of emergency dyspnea was observed in the COVID-19 cohort, with the biggest proportional change observed in Lodz (by 4.5\%) and the smallest in Poznan (by $0.25 \%$ ). There was no statistically significant difference in the incidence proportion between the time cohorts. The incidence proportion of surgical procedures due to laryngological dyspnea from head and neck cancer is summarized in Table 1.

Table 1

Number of tracheotomy procedures in pre-COVID-19 and COVID-19 time cohorts.

\begin{tabular}{|c|c|c|c|c|}
\hline Parameter & $\begin{array}{l}\text { Clinical } \\
\text { center }\end{array}$ & $\begin{array}{l}\text { Pre- } \\
\text { COVID-19 } \\
\text { Cohort }\end{array}$ & $\begin{array}{l}\text { COVID- } \\
19 \\
\text { Cohort }\end{array}$ & Change \\
\hline \multirow{4}{*}{$\begin{array}{l}\text { Number of tracheotomy procedures for acute } \\
\text { dyspnea from oncologic disease (TRA) }\end{array}$} & Lodz & 30 & 40 & $+33 \%$ \\
\hline & Poznan & 15 & 17 & $+13 \%$ \\
\hline & Bydgoszcz & 11 & 13 & $+18 \%$ \\
\hline & Gdansk & 3 & 7 & $+133 \%$ \\
\hline \multirow[t]{4}{*}{ Total number of ENT surgeries (SUR) } & Lodz & 1052 & 544 & $-48 \%$ \\
\hline & Poznan & 1520 & 1371 & $-10 \%$ \\
\hline & Bydgoszcz & 404 & 287 & $-29 \%$ \\
\hline & Gdansk & 419 & 342 & $-18 \%$ \\
\hline \multirow[t]{4}{*}{ Incidence proportion (TRA/SUR) } & Lodz & $2.85 \%$ & $7.35 \%$ & $+4.5 \%$ \\
\hline & Poznan & $0.99 \%$ & $1.24 \%$ & $\stackrel{+}{0.25 \%}$ \\
\hline & Bydgoszcz & $2.72 \%$ & $4.53 \%$ & $+\overrightarrow{1}+81 \%$ \\
\hline & Gdansk & $0.72 \%$ & $2.05 \%$ & $\begin{array}{l}+ \\
1.33 \%\end{array}$ \\
\hline
\end{tabular}

The aim of the analysis was not to investigate the differences between ENT centers, and the huge number of tracheotomies in Lodz is related to it being the only emergency department in the region with a long tradition of oncology. In Gdansk, there are three other ENT emergency departments with such an oncological profile. 
The rise in incidence is best seen in the centers that had the greatest limitations due to local restrictions in planned surgeries; in Lodz, the number of planned surgeries changed by $-48 \%$ between the periods, causing a significant increase in emergency tracheotomy procedures due to laryngological dyspnea in the course of an oncological disease, while for centers which noted less significant changes in the total number of planned surgeries (Poznan, Gdansk), the increase the increase in airway restoration procedures was less visible $(0.25 \%$ and $1.33 \%$ respectively).

All the University Clinical Centers noted an increase in the total number of tracheotomy procedures in patients with head and neck neoplasms, with the greatest increase between the pre-COVID-19 and COVID19 periods in Gdansk, by 133\%, and in Lodz, by 33\%. In Poznan and Gdansk, there was the smallest percentage decrease in the total number of all planned surgeries performed in the COVID-19 period. In these two Departments, the percentage proportion increase in tracheotomies was lower than in Łódź and Bydgoszcz. The increase in the percentage of tracheotomies as a total of surgeries performed was the most pronounced in Łódź and Bydgoszcz, but these Departments were also affected by the longest period of interruption of specialist services due to the pandemic, with only urgent cases being admitted, which constituted a growing percentage of the number of total surgeries.

In Łódź and Bydgoszcz, there were similar treatment restrictions. In the COVID-19 period, there was a reduction of up to $50 \%$ in the number of beds, appointments numbers at outpatient clinics were reduced, there was limited access to the operating room (only 2 or 3 days a week instead of 5), and there was an increased inflow of urgent patients from the region due to the closure of other ENT departments.

Epidemiological data for patients treated by urgent open tracheotomies in both pre-COVID-19 and COVID19 cohorts are presented and compared in Table 2. To represent the urgency of the procedure, the duration of symptoms of dyspnea was broken down into those that developed in a month or less and longer than one month. In the pre-COVID-19 period, $66 \%$ of patients presented with symptoms developing for more than a month, whereas in the COVID-19 period, as much as $78 \%$ of patients fell into this category. This observation was statistically significant $(p=0.04)$. Neither the advancement of the disease nor the localization of the primary tumor differed significantly between the groups. However, there was a higher incidence of laryngeal and laryngopharyngeal cancer in COVID-19 compared to the pre-COVID-19 period ( $63 \%$ vs. $75 \%$, respectively). Other analyzed parameters, such as concomitant disorders categorized by system (cardiovascular, respiratory, neurological, number of cardiovascular incidents, diabetes mellitus) or "other", as well as concurrent neoplasms, were not found to be significantly different between the time cohorts. Obesity or malnutrition was not a significant factor, since the median BMI in the pre-COVID-19 cohort was 22.5 (IQR 5.2) and in the COVID-19 cohort 23.53 (IQR 5.54), both of which can be interpreted as normal BMls. 
Table 2

Characteristics of patients who developed dyspnea due to head and neck cancer and were treated with a tracheotomy.

\begin{tabular}{|c|c|c|c|}
\hline & $\begin{array}{l}\text { Pre-COVID-19 } \\
\text { Cohort }\end{array}$ & $\begin{array}{l}\text { COVID-19 } \\
\text { Cohort }\end{array}$ & $\mathrm{p}$ value \\
\hline & Total $\mathbf{N}=59$ & Total $\mathbf{N}=77$ & \\
\hline Primary tumor site & & & $p=0.34^{*}$ \\
\hline Larynx and laryngopharynx & $37(63 \%)$ & $58(75 \%)$ & \\
\hline Oral cavity and tongue & $7(12 \%)$ & $8(10 \%)$ & \\
\hline Oropharynx & $10(17 \%)$ & $6(8 \%)$ & \\
\hline Other (thyroid, esophagus, lung) & $5(9 \%)$ & $5(7 \%)$ & \\
\hline Tumor advancement & & & $p=0.52^{\star}$ \\
\hline T2 & $3(5 \%)$ & $3(4 \%)$ & \\
\hline T3 & $13(23 \%)$ & $24(32 \%)$ & \\
\hline T4 & $41(72 \%)$ & $49(65 \%)$ & \\
\hline \multicolumn{4}{|l|}{ Comorbidities } \\
\hline Diabetes & $7(12 \%)$ & $11(14 \%)$ & $\begin{array}{l}p= \\
0.67 \star \star\end{array}$ \\
\hline Other neoplasm & $6(10 \%)$ & $7(9 \%)$ & $\begin{array}{l}\mathrm{p}= \\
0.83^{\star \star}\end{array}$ \\
\hline Respiratory disease & $2(3 \%)$ & $6(8 \%)$ & $p=0.24^{\star}$ \\
\hline Cardiovascular disease & $22(37 \%)$ & $26(34 \%)$ & $\begin{array}{l}p= \\
0.67 \star \star\end{array}$ \\
\hline Tracheotomy under general anesthesia & $38(64 \%)$ & $43(56 \%)$ & $p=0.31^{\star}$ \\
\hline Gender & & & $\begin{array}{l}\mathrm{p}= \\
0.82^{\star \star}\end{array}$ \\
\hline Male & $45(76 \%)$ & $60(78 \%)$ & \\
\hline Female & $14(24 \%)$ & $17(22 \%)$ & \\
\hline $\begin{array}{l}\text { Time from first symptoms to hospital } \\
\text { admission }\end{array}$ & & & $p=0.04^{*}$ \\
\hline More than 30 days & $30(66 \%)$ & 60 (78\%) & \\
\hline
\end{tabular}

*two-tailed Fischer's exact test with Freeman-Halton extension **Pearson's Chi-squared test with Yates's correction for continuity 


\begin{tabular}{|llll|}
\hline & $\begin{array}{l}\text { Pre-COVID-19 } \\
\text { Cohort } \\
\text { Total N=59 }\end{array}$ & $\begin{array}{l}\text { COVID-19 } \\
\text { Cohort } \\
\text { Total N=77 }\end{array}$ & p value \\
\hline 8 to 30 days & $10(17 \%)$ & $3(4 \%)$ & \\
\hline Less than 7 days & $10(17 \%)$ & $14(18 \%)$ & \\
\hline Acute dyspnea duration & & & $0.65^{\star \star}$ \\
\hline $1-2$ days & $21(55 \%)$ & $36(62 \%)$ & \\
\hline $3-7$ days & $17(45 \%)$ & $22(38 \%)$ & \\
\hline Telemedicine consultations & & & \\
\hline None & $45(76 \%)$ & $22(26 \%)$ & \\
\hline One & $14(24 \%)$ & $38(49 \%)$ & \\
\hline More than one & 0 & $17(22 \%)$ & \\
\hline *two-tailed Fischer's exact test with Freeman-Halton extension & & \\
\hline **Pearson's Chi-squared test with Yates's correction for continuity & & \\
\hline
\end{tabular}

As the difficulties of intubating a patient with acute dyspnea limit the ability to visualize the glottis, the number of tracheotomies performed under general anesthesia dropped in favor of those conducted under local anesthesia during COVID-19 (56\% vs $64 \%$ pre-COVID-19). The epidemiological characteristics of the time cohorts are summarized in Table 2.

Regarding telemedical services, which were uncommon pre-pandemic, out of 59 patients, only 14 individuals (24\%) had received a telemedical consultation before admission to hospital, and all those cases presented with symptoms that had been developing for more than 30 days. In comparison, in the COVID-19 cohort, most patients received a telemedicine consultation from their primary care facility (55 patients, $71 \%$ ), out of which $49 \%$ of patients received at least one and $22 \%$ more than one teleconsultation. Analyzing symptom duration in this cohort of patients, only one individual with symptoms presenting for less than seven days received a teleconsultation. Patients who presented with symptoms developing for more than seven days, but less than 30 days, received at least one teleconsultation in $64 \%$ of all those cases.

Considering the time it took to develop acute dyspnia in the COVID-19 group and the number of teleconsultations, in the urgent group (1-2 days of dyspnea), 21 patients $(61 \%)$ received one teleconsultation and six (17\%) more than one. In contrast, in the group which developed dyspnea for more than three days, 22 patients $(36 \%)$ received at least one, while almost $50 \%$ of individuals received two or more teleconsultations. This observation was statistically significant (Fischer's exact test with 
Freeman-Halton extension $p=0.036)$. In the pre-COVID-19 period, all individuals who received a teleconsultation (14 patients) presented with dyspnea developing over more than seven days.

\section{Discussion}

To the best of our knowledge, we have presented the first cohort analysis of the therapeutic treatment offered by emergency ENT units during a pandemic, in terms of acute dyspnea in HNC patients. We based our observations and conclusions on a comparison of the patients admitted in the periods September-February 2019/2020 and 2020/2021. As an overview of the total medical activities of the ENT department, we have summarized the number of services provided. Overall, a decrease in planned surgeries was observed, which ranged across different centers from $-48 \%$ to $-10 \%$, depending on the local exacerbation of the pandemic and locally imposed healthcare restrictions on the normal functioning of hospitals.

Our analysis of four University Departments of Otolaryngology showed that the number of urgent tracheotomies in HNC patients increased in all of them, but proportionally, the most in those where the primary activity was limited. On the one hand, it proves that the system of admissions and life-saving procedures was maintained, although some of these Departments had been converted to meet the needs of the pandemic. On the other hand, however, the greater the involvement in combating the pandemic, the fewer planned interventions were carried out, and the higher the percentage of emergency procedures. A large proportion of patients awaiting planned surgeries had them postponed, which showed that capacity was fixed, with no possibility to expand the Department's activity. Our findings have been partially reflected in the recent literature. The coronavirus pandemic, and the subsequent need for disease transmission mitigation efforts, significantly altered the delivery of cancer care [1, 2]. In developed countries, the use of inpatient care and subsequent hospitalization deficit in oncology was estimated to be $7 \%-35 \%$ [19-22]. All oncological subspecialties in the US experienced significant decreases in new patient visits and surgery capacity during COVID-19 [23], with a $25 \%$ reduction in newly diagnosed head and neck malignancies [24].

In our experience, the limitations of cancer care were not reflected in the number and proportion of urgent tracheotomies between the two cohorts. Regardless of their place of residence, oncological patients with extreme dyspnea are mainly neglected health cases. Another observation is the change in the proportion of primary lesions and the overrepresentation of laryngeal cancer. This is probably related to the fact that during the pandemic, primaries with a rapid progression could not wait anyway, while those with slowly developed cancers, who adapted to the dyspnea, more often reported in an extreme state.

Our results point out that telemedicine was a popular means of providing healthcare during the pandemic, which has also been observed across different healthcare systems [17, 22, 25]. Patients developing acute, dynamic dyspnea mostly had one telemedical consultation, which led to an immediate referral to the hospital. A full analysis of the effects of telemedicine is limited, due to missing data regarding the time between the actual consultation and the patient's date of admission to the hospital. 
Nonetheless, patients who presented with acute dyspnea and who had been directed to the hospital constituted a minority of cases in the COVID-19 cohort. Comparing the pre-pandemic use of telemedicine to the pandemic period, all the individuals in the COVID-19 cohort in this study, who underwent a telemedical consultation, developed symptoms over a longer period and constituted a minority of all cases in that cohort. Possibly, the lack of standardized IT platforms results in serious challenges in replacing frontal visits, often making a concrete reduction in patients' hospital access unfeasible [22]. Although telemedicine may improve healthcare access, patient preferences, technology-related barriers, and limitations regarding cancer surveillance must be addressed moving forward [25]. When given a choice, patients with head and neck cancer preferred in-person visits over telemedicine [25].

Although the aim of the analysis was not to investigate the differences between the four University Departments, some aspects are worth highlighting. Initial surgical load in the pre-COVID-19 period, the number of emergency departments in the given regions, and breaks/closures due to the pandemic constitute some reasons for the differences in the numbers of procedures. The density of ENT departments in the region and round-the-clock emergency care availability, a reduction in available beds, fewer outpatient clinic appointments, as well as limited access to the operating room also mattered.

Strengths and limitations of the study

To the best of our knowledge, this study constitutes the largest clinical group analyzed regarding emergency department services related to severe dyspnea in HNC patients.

One of the biggest limitations of this study was the relatively small study group, which was then divided into two Cohorts. Sample sizes below 5 individuals for some variables required the use of the conservative Fischer's exact test.

In summary, the number of tracheotomy procedures in HNC patients was higher in the COVID-19 period. This may indicate both the higher advancement of a larger number of patients, as well as higher reporting to the four analyzed Departments, probably due to the limited availability of other healthcare providers. However, the first theory should be considered more likely because HNC patients are directed to the analyzed University Departments anyway. However, this premise will require confirmation in subsequent analyses, i.e., the total number of patients from the oncological pathway.

The degree of advancement of HNC during urgent tracheotomy is the same between the cohorts, which is logical, but the higher percentage of tracheotomies performed under local anesthesia is noteworthy. It is a category of extremely urgent procedures with complete airway obstruction. This means that in these patients, intubation was attempted, but the glottis was not visualized, so the tracheotomy was performed immediately, or the procedure was even performed in the Emergency Department, without intubation attempts.

\section{Conclusions}


In ENT departments, the referral system should be reorganized, the treatment capacity for HNC cases should be adjusted, and there should be a reserve for more extensive resection and reconstruction surgeries.

\section{Abbreviations}

HNC - Head and Neck Cancer, IQR - Interquartile range

\section{Declarations}

\section{Ethics approval}

This study was conducted in accordance to the Declaration of Helsinki, the study design was approved by the Bioethics Comitee of the Medical University of Lodz.

\section{Consent for publication}

Not applicable

\section{Availability of data}

The datasets used and/or analysed during the current study are available from the corresponding author on reasonable request.

\section{Competing interests}

The authors declare that they have no competing interests

\section{Funding}

The funding for this research was provided by the Medical University of Lodz on an internal grant. The funds were used for publication fees.

\section{Authors' contributions}

Conceptualization, M.W., W.P., P.B., B.M., Methodology, M.W., W.P., P.B., B.M., O.R.; Investigation, P.P., B.Z., M.B., M.K., J.P., P.S., M.S.; Resources, P.P., B.Z., M.B., M.K., J.P., P.S., M.S.; Writing - Original Draft Preparation, M.W., W.P., P.B., B.M., O.R.; Writing - Review \& Editing, M.W., W.P., P.B., B.M.; Visualization, O.R., M.B, M.K. All authors read and approved the final manuscript.

\section{Acknowledgements}

Not applicable

\section{References}


1. Knoerl R, Phillips CS, Berfield J, et al. Lessons learned from the delivery of virtual integrative oncology interventions in clinical practice and research during the COVID-19 pandemic. Support Care Cancer 2021; 1 .

2. Snyder RA. A noticeable absence. Cancer. Epub ahead of print 2021. DOI: 10.1002/cncr.33291.

3. Reeves JJ, Hollandsworth HM, Torriani FJ, et al. Rapid response to COVID-19: Health informatics support for outbreak management in an academic health system. JAMIA Open. 2020;27:853-9.

4. Jeffery MM, D'Onofrio G, Paek $\mathrm{H}$, et al. Trends in Emergency Department Visits and Hospital Admissions in Health Care Systems in 5 States in the First Months of the COVID-19 Pandemic in the US. JAMA Intern Med. 2020;180:1328-33.

5. Murphy CT, Galloway TJ, Handorf EA, et al. Survival impact of increasing time to treatment initiation for patients with head and neck cancer in the United States. J Clin Oncol. 2016;34:169-78.

6. Xiao R, Ward MC, Yang K, et al. Increased pathologic upstaging with rising time to treatment initiation for head and neck cancer: A mechanism for increased mortality. Cancer. 2018;124:1400-14.

7. Guttmann DM, Kobie J, Grover S, et al. National disparities in treatment package time for resected locally advanced head and neck cancer and impact on overall survival. Head Neck. 2018;40:114755 .

8. O'Connell DA, Seikaly H, Isaac A, et al. Recommendations from the Canadian Association of Head and Neck Surgical Oncology for the Management of Head and Neck Cancers during the COVID-19 pandemic. Otolaryng Head Neck, 49. Epub ahead of print July 2020. DOI: 10.1186/s40463-02000448-z.

9. LL M, CHQ F, GN M, et al. The hidden curve behind COVID-19 outbreak: the impact of delay in treatment initiation in cancer patients and how to mitigate the additional risk of dying-the head and neck cancer model. Cancer Causes Control: CCC, 32. Epub ahead of print 2021. DOI: 10.1007/S10552-021-01411-7.

10. Ivanyi P, Park-Simon T, Christiansen $\mathrm{H}$, et al. Protective measures for patients with advanced cancer during the Sars-CoV-2 pandemic: Quo vadis? Clin Exp Metastasis. Epub ahead of print 2021. DOI: 10.1007/s10585-021-10083-1.

11. Sidaway P. COVID-19 and cancer: what we know so far. Nature Reviews Clinical Oncology. 2020;17:336.

12. Lee AJX, Purshouse K. COVID-19 and cancer registries: learning from the first peak of the SARS-CoV2 pandemic. Br J Cancer. 2021;124:1777-84.

13. Day AT, Sher DJ, Lee RC, et al. Head and neck oncology during the COVID-19 pandemic: Reconsidering traditional treatment paradigms in light of new surgical and other multilevel risks. Oral Oncol; 105. Epub ahead of print June 2020. DOI: 10.1016/j.oraloncology.2020.104684.

14. Han AY, Miller JE, Long JL, et al. Time for a Paradigm Shift in Head and Neck Cancer Management During the COVID-19 Pandemic. Otolaryng Head Neck. 2020;163:447-54.

15. Maniakas A, Jozaghi $Y$, Zafereo ME, et al. Head and neck surgical oncology in the time of a pandemic: Subsite-specific triage guidelines during the COVID-19 pandemic. In: Head Neck. John 
Wiley and Sons Inc.; 2020. pp. 1194-201.

16. de Almeida JR, Noel CW, Forner D, et al. Development and validation of a Surgical Prioritization and Ranking Tool and Navigation Aid for Head and Neck Cancer (SPARTAN-HN) in a scarce resource setting: Response to the COVID-19 pandemic. Cancer. 2020;126:4895-904.

17. Banerjee S, Voliotidis D, Parvin L, et al. Telephone triage of suspected head and neck cancer patients during the coronavirus disease 2019 pandemic using the Head and Neck Cancer Risk Calculator version 2. J Laryngol Otol. 2021;135:241-5.

18. El-Naggar AK, Chan JK, Grandis JR, et al. WHO Classification of Head and Neck Tumours. Fourth edition. Lyon, France: International Agency for Research on Cancer (IARC), https://apps.who.int/bookorders/anglais/detart1.jsp?codlan=1\&codcol=70\&codcch=4009 (2017, accessed 14 January 2020).

19. Bollmann A, Hohenstein S, Pellissier V, et al. Utilization of in- And outpatient hospital care in Germany during the Covid-19 pandemic insights from the German-wide Helios hospital network. PLoS ONE. 2021;16:e0249251.

20. Rao V, Arakeri G, Subash A, et al. Decreased Cancer Consultations in the COVID-19 Era: A Concern for Delay in Early Cancer Diagnosis in India. JCO Glob Oncol. 2021;7:408-9.

21. Santi Id L, Golinelli D, Tampieri A, et al. Non-COVID-19 patients in times of pandemic: Emergency department visits, hospitalizations and cause-specific mortality in Northern Italy. PLOS ONE. 2021;16:e0248995.

22. Indini A, Pinotti G, Artioli F, et al. Management of patients with cancer during the COVID-19 pandemic: The Italian perspective on the second wave. Eur J Cancer. 2021;148:112-6.

23. Gazivoda V, Greenbaum A, Roshal J, et al. Assessing the immediate impact of COVID-19 on surgical oncology practice: Experience from an $\mathrm{NCl}$-designated Comprehensive Cancer Center in the Northeastern United States. J. Surg. Oncol. Epub ahead of print 2021. DOI: 10.1002/jso.26475.

24. Kiong KL, Diaz EM, Gross ND, et al. The impact of COVID-19 on head and neck cancer diagnosis and disease extent. Head Neck. 2021;43:1890-7.

25. Fassas S, Cummings E, Sykes KJ, et al. Telemedicine for head and neck cancer surveillance in the COVID-19 era: Promise and pitfalls. Head Neck. 2021;43:1872-80. 